\title{
Results of the monitoring of the effectiveness of repellents against wild boar in the fields
}

\section{Wyniki monitoringu skuteczności działania substancji zapachowych do odstraszania dzika od upraw polowych}

\author{
Paweł Węgorek, Joanna Zamojska, Andrzej Bandyk, Paweł Olejarski
}

\section{Summary}

The effectiveness of repellent action of selected scent repellents available on the market in Poland against wild boars was tested in the experiments. The study was conducted in three populations of animals of different density and various degrees of human impact. The study areas were forage plots, separate areas of maize fields or the whole fields of corn. The results of the effectiveness of repellents against selected populations of wild boar in the forage plots showed that none of the products protected sufficiently for a long time due to a habit of constant feeding on corn at this particular site that animals developed over time. The experiments clearly show that in most cases the resistance of wild boar to tested repellents appears relatively quickly. The phenomenon is permanent and animals, which learn quickly, after a short period of time do not respond to the scent repellents. The results are similar for the different populations of tested animals. This indicates that the fast acquisition of resistance to scent repellents is a feature of wild boars.

Key words: biocides; repellents; game species; wild boars

\section{Streszczenie}

Badano skuteczność odstraszania dzików od upraw polowych przy pomocy wybranych repelentów zapachowych dostępnych na polskim rynku. Doświadczenia prowadzono na trzech populacjach zwierząt, w miejscach o różnym zagęszczeniu populacji dzika i różnym stopniu antropopresji. Teren badań stanowiły poletka żerowe zwierzyny, wydzielone powierzchnie pól kukurydzy lub całe pola kukurydzy. Wyniki skuteczności działania repelentów na wybrane populacje dzika na poletkach żerowych wykazały, że żaden z badanych środków nie zabezpieczał skutecznie przez dłuższy czas powierzchni, do których dziki były przyzwyczajone poprzez stałe dokarmianie nasionami kukurydzy. Przeprowadzone badania wyraźnie wskazują, że w większości przypadków odporność na testowane repelenty występuje stosunkowo szybko, jest trwała i szybko uczące się zwierzęta nie reagują, po krótkim okresie czasu, na zapachowe repelenty.

Słowa kluczowe: środki biobójcze; repelenty; szkody łowieckie; dzik

Instytut Ochrony Roślin - Państwowy Instytut Badawczy

Władysława Węgorka 20, 60-318 Poznań

p.wegorek@iorpib.poznan.pl 


\section{Wstęp / Introduction}

W związku z narastającym problemem szkód powodowanych przez niektóre gatunki ssaków łownych w uprawach rolniczych i leśnych obecność na rynku substancji chemicznych skutecznych w odstraszaniu dzika (Sus scrofa L.) jest bardzo pożądana (Bibier i Ruf 2005; Kamieniarz i wsp. 2008; Budny i wsp. 2010). Obecnie w Polsce nie ma zarejestrowanych i dopuszczonych do obrotu środków ochrony roślin o działaniu repelentnym w stosunku do dzika i innych gatunków zwierząt łownych. $\mathrm{W}$ praktyce rolniczej stosuje się jednak rozmaite kompozycje zapachowe nie będące środkami ochrony roślin, a dopuszczone ustawowo do stosowania jako środki biobójcze. W myśl Ustawy z dnia 13 września 2002 r. o produktach biobójczych (Dz. U. nr 175, poz. 1433 z późn. zm.) są to substancje czynne lub preparaty zawierające co najmniej jedną substancję czynną w postaciach, w jakich są dostarczone użytkownikowi, przeznaczone do niszczenia, odstraszania, unieszkodliwwiania, zapobiegania działaniu lub kontrolowania w jakikolwiek inny sposób organizmów szkodliwych przez działanie chemiczne lub biologiczne. Środki ochrony roślin o identycznym lub podobnym składzie chemicznym oraz działaniu stosowane były w Polsce w przeszłości, a Instytut Ochrony Roślin - Państwowy Instytut Badawczy (IOR - PIB) w Poznaniu monitorował ich skuteczność (Węgorek i Giebel 2008). Badania te wykazywały na ogół niewielką skuteczność i zmienność w reakcji różnych populacji tego samego gatunku ssaków łownych na takie same substancje zapachowe, co wiązano $\mathrm{z}$ procesami adaptacji oraz procesami uczenia się oraz zapamiętywania (Drickamer i Vessey 1982; Fruziński 1992).

Wyniki obecnych badań wskazują na niewielką zmienność reakcji dzika na badane substancje zapachowe. $\mathrm{W}$ pracy przedstawiono wyniki monitoringu skuteczności biologicznego działania wybranych preparatów biobójczych w odstraszaniu tych zwierząt od upraw kukurydzy i specjalnych powierzchni żerowych, gdzie stosuje się stałe dokarmianie.

\section{Materiały i metody / Materials and methods}

Badano skuteczność odstraszania dzików (S. scrofa) od upraw polowych przy pomocy wybranych repelentów zapachowych dostępnych na rynku (Hukinol AL, Kornitol, BioTec). Badania prowadzono na trzech populacjach zwierząt, w miejscach o różnym zagęszczeniu populacji dzika i różnym stopniu antropopresji: populacja 1 - Winna Góra, zagęszczenie populacji około 15 dzików/1000 ha, silna antropopresja, rejon polny; populacja 2 - Wałcz, zagęszczenie około 20 dzików/1000 ha słaba antropopresja, rejon leśny; populacja 3 - Skoki, zagęszczenie populacji około 25 dzików/1000 ha, średnia antropopresja, rejon polno-leśny.

Terenem badań skuteczności repelentów zapachowych były poletka żerowe zwierzyny, wydzielone powierzchnie pól kukurydzy lub całe pola kukurydzy. Pola wybrane do doświadczeń należały do Ośrodka Hodowli Zwierzyny, IOR - PIB oraz prywatnych rolników.
Doświadczenia prowadzono w latach 2012 i 2013, w okresie od marca do sierpnia każdego roku. W okresie obserwacji skuteczności działania poszczególnych repelentów, odnotowywano obecność zwierząt na chronionych powierzchniach, ich żerowanie, a na polach $\mathrm{z}$ uprawą kukurydzy określano powierzchnię zredukowaną, wyrażaną $\mathrm{w}$ procentach powierzchni zredukowanej w odniesieniu do kontroli.

Doświadczenia nad skutecznością działania repelentów prowadzono nasączając nimi przy pomocy pipety kawałki filcu, każdorazowo $1 \mathrm{ml}$ środka na jeden skrawek materiału o powierzchni $6 \mathrm{~cm}^{2}$ i przytwierdzając je do palików rozmieszczonych wokół chronionej powierzchni pól. Paliki z naniesionym środkiem umieszczano w rozstawie 30 metrów, a zabieg nasączania powtarzano co 5 dni. Obserwacje prowadzono codziennie przez okres $10 \mathrm{dni}$ od momentu pierwszej aplikacji, a następnie co 5 dni po kolejnych aplikacjach, odnotowując obecność dzików na chronionej powierzchni pól, ich żerowanie i przyrost powierzchni zredukowanej. Okres obserwacji dla każdego doświadczenia wynosił $50 \mathrm{dni}$. Wyniki porównywano z polami kontrolnymi lub wydzielonymi powierzchniami kontrolnymi, na których nie prowadzono chemicznej ochrony. W dniu rozpoczęcia doświadczenia na polach, o ile wcześniej żerowały dziki, odnotowywano rozmiar szkód już zaistniałych. Pola kontrolne ze względu na silny zapach badanych repelentów oddalone były od powierzchni chronionych o około $500 \mathrm{~m}$.

W okresie prowadzenia doświadczeń odnotowywano stan pogody i temperaturę powietrza. Przy każdej kontroli szacowano wielkość uszkodzenia upraw według stanu aktualnego w dniu szacowania, co pozwalało wyliczyć przyrost wielkości szkód powstałych w okresie pomiędzy kolejnymi kontrolami, a także wyliczenie łącznej powierzchni zniszczonej uprawy.

\section{Wyniki i dyskusja / Results and discussion}

Wyniki skuteczności działania repelentów na wybrane populacje dzika na poletkach żerowych wykazały, że żaden $\mathrm{z}$ badanych środków nie zabezpieczał skutecznie przez dłuższy czas powierzchni, do których dziki były przyzwyczajone poprzez stałe dokarmianie nasionami kukurydzy. W przypadku populacji Winna Góra, okres skutecznego działania repelentów wyniósł, zarówno w 2012, jak i 2013 roku 2-3 doby tylko w początkowej fazie doświadczenia (tab. 1). Przy powtórzonych zabiegach efekt odstraszania dzików wynosił maksymalnie 1 dobę. Dla populacji Wałcz skuteczne działanie repelentów w początkowym okresie badań wynosiło 3-4 doby, a dla populacji Skoki 1-4 doby (tab. 1). Powtórzenie aplikacji repelentami, niezależnie od badanej populacji dawało maksymalnie jednodniowy (1 doba) efekt odstraszający. Uzyskane wyniki ochrony poletek żerowych świadczą o bardzo słabej, krótkotrwałej reakcji wszystkich badanych populacji na odstraszające działanie badanych kompozycji zapachowych. Można przypuszczać, że początkowe, skuteczne działanie spowodowane było ostrożnością zwierząt w stosunku do nowego w ich środowisku zapachu, ale nie wywoływało trwałych reakcji lękowych (Wiepkema 1986; 
Tabela 1. Skuteczność działania repelentów na poletkach żerowych w latach 2012-2013

Table 1. Results of the effectiveness of the repellents action on a feeding field in years 2012-2013

\begin{tabular}{|c|c|c|c|c|c|c|}
\hline \multirow[t]{2}{*}{$\begin{array}{l}\text { Preparat } \\
\text { Product }\end{array}$} & \multicolumn{3}{|c|}{$\begin{array}{l}\text { Okres skutecznego działania po pierwszej aplikacji } \\
\text { [doby] } \\
\text { The period of effective action after first application } \\
\text { [days] } \\
2012-2013\end{array}$} & \multicolumn{3}{|c|}{$\begin{array}{l}\text { Okres skutecznego działania po drugiej i kolejnych } \\
\text { aplikacjach } \\
\text { [doby] } \\
\text { The period of effective action after second and next } \\
\text { applications } \\
\text { [days] } \\
2012-2013\end{array}$} \\
\hline & $\begin{array}{c}\text { populacja } 1 \\
\text { population } 1\end{array}$ & $\begin{array}{c}\text { populacja } 2 \\
\text { population } 2 \\
\end{array}$ & $\begin{array}{c}\text { populacja } 3 \\
\text { population } 3 \\
\end{array}$ & $\begin{array}{c}\text { populacja } 1 \\
\text { population } 1\end{array}$ & $\begin{array}{c}\text { populacja } 2 \\
\text { population } 2 \\
\end{array}$ & $\begin{array}{c}\text { populacja } 3 \\
\text { population } 3\end{array}$ \\
\hline Kontrola - Control & $0 / 0$ & $0 / 0$ & $0 / 0$ & $0 / 0$ & $0 / 0$ & $0 / 0$ \\
\hline Hukinol AL & $3 / 3$ & $4 / 3$ & $4 / 2$ & $0 / 1$ & $1 / 0$ & $1 / 1$ \\
\hline Kornitol & $2 / 1$ & $4 / 3$ & $2 / 1$ & $0 / 0$ & $0 / 1$ & $1 / 1$ \\
\hline BioTec & $2 / 1$ & $4 / 3$ & $3 / 1$ & $1 / 0$ & $0 / 1$ & $1 / 0$ \\
\hline
\end{tabular}

Tabela 2. Skuteczność działania repelentów na polach kukurydzy w latach 2012-2013

Table 2. Results of the effectiveness of the repellents action on maze fields - years 2012-2013

\begin{tabular}{|c|c|c|c|c|c|c|c|c|c|}
\hline \multirow[t]{2}{*}{$\begin{array}{l}\text { Preparat } \\
\text { Product }\end{array}$} & \multicolumn{3}{|c|}{$\begin{array}{l}\text { Obecność dzików } \\
\text { na chronionej uprawie w okresie } \\
\text { doświadczeń } \\
\text { The presence of wild boars on protected } \\
\text { area during experiments } \\
\text { 2012-2013 }\end{array}$} & \multicolumn{3}{|c|}{$\begin{array}{c}\text { Żerowanie dzików } \\
\text { na chronionej uprawie w okresie } \\
\text { doświadczeń } \\
\text { Wild boars’ feeding on protected area } \\
\text { during experiments } \\
\text { 2012-2013 } \\
\end{array}$} & \multicolumn{3}{|c|}{$\begin{array}{c}\text { Powierzchnia zredukowana } \\
\text { Reduced area } \\
{[\%]} \\
2012-2013\end{array}$} \\
\hline & $\begin{array}{c}\text { populacja } \\
\text { population } \\
1\end{array}$ & $\begin{array}{l}\text { populacja } \\
\text { population } \\
2\end{array}$ & $\begin{array}{l}\text { populacja } \\
\text { population } \\
3\end{array}$ & $\begin{array}{c}\text { populacja } \\
\text { population } \\
1\end{array}$ & $\begin{array}{l}\text { populacja } \\
\text { population } \\
2\end{array}$ & $\begin{array}{c}\text { populacja } \\
\text { population } \\
3\end{array}$ & $\begin{array}{c}\text { populacja } \\
\text { population } \\
1\end{array}$ & $\begin{array}{c}\text { populacja } \\
\text { population } \\
2\end{array}$ & $\begin{array}{l}\text { populacja } \\
\text { population } \\
3\end{array}$ \\
\hline $\begin{array}{l}\text { Kontrola } \\
\text { Control }\end{array}$ & tak - yes & tak - yes & tak - yes & tak - yes & tak-yes & tak-yes & $60 / 20$ & $30 / 10$ & $20 / 15$ \\
\hline $\begin{array}{l}\text { Hukinol } \\
\mathrm{AL}\end{array}$ & tak - yes & tak - yes & tak - yes & tak - yes & tak - yes & tak-yes & $45 / 20$ & $25 / 10$ & $5 / 10$ \\
\hline Kornitol & tak-yes & tak - yes & tak - yes & tak - yes & tak - yes & tak-yes & $40 / 25$ & $30 / 15$ & $15 / 15$ \\
\hline BioTec & tak-yes & tak-yes & tak-yes & tak - yes & tak - yes & tak-yes & $45 / 20$ & $20 / 10$ & $5 / 25$ \\
\hline
\end{tabular}

Węgorek 2011). Prawdopodobnie możliwość zdobycia pokarmu w innych miejscach spowodowała kilkudniowe zrezygnowanie $\mathrm{z}$ przebywania $\mathrm{i}$ żerowania $\mathrm{w}$ miejscach chronionych repelentami. Po szybkim przełamaniu ostrożności przed nowymi zapachami zwierzęta w dalszym okresie prowadzenia doświadczeń ignorowały repelenty i nie zaprzestawały przebywania oraz żerowania w obrębie zapachowego oddziaływania badanych środków. Jest to typowe zachowanie u zwierząt wyższych w warunkach powtarzania się tylko jednego sygnału oraz braku następstw i motywacji do ucieczki w dalszym łańcuchu bodźców kluczowych, wywołujących instynktowną ucieczkę (Godzińska 1992; Andersen i wsp. 2006; Węgorek 2011). W przypadku bodźców zapachowych, w sekwencji zachowań powodujących ucieczkę z miejsca zagrożenia, $\mathrm{u}$ dzika początkowo pojawia się odruch orientacyjny, następnie zwiększenie uwagi, niepokój, lęk i na końcu ucieczka na bezpieczną odległość.

Podobne wyniki doświadczeń, świadczące o adaptacji dzików do repelentów zapachowych uzyskano w przypadku ochrony upraw kukurydzy (tab. 2). W 2012 roku efekty zastosowania badanych środków ograniczyły szkody w porównaniu do kontroli o 5-20\%, jednak nie wyeliminowały ich całkowicie. Te same środki zastosowane w 2013 roku nie ograniczyły szkód powodowanych przez dziki z wyjątkiem Hukinolu AL, gdzie ograniczenie szkód w porównaniu z kontrolą wyniosło $5 \% \mathrm{w}$ odniesieniu do populacji Skoki.

Wyniki doświadczeń wskazują jednoznacznie na szybką i trwałą adaptację (habituację) dzików w odniesieniu do substancji zapachowych stosowanych w badanych repelentach. Reakcje badanych populacji dzika związane są z ich uczeniem się oraz pamięcią i prawdopodobnie mają charakter zmian synaptycznych warunkujących te procesy (McClintock 2002). Dzik charakteryzuje się ewolucyjnie wykształconą wysoką organizacją centralnego układu nerwowego, co ułatwia temu gatunkowi funkcjonowanie w cywilizacyjnie zmienionym środowisku (Godzińska 1992; Jezierski 2002; Geisser i Reyer 2004).

\section{Wnioski / Conclusions}

1. Przeprowadzone doświadczenia wyraźnie wskazują, iż w większości przypadków odporność na testowane repelenty występuje stosunkowo szybko, jest trwała i szybko uczące się zwierzęta, po krótkim okresie czasu, na zapachowe repelenty nie reaguja. 
2. Uzyskane wyniki są zbliżone dla różnych populacji badanych zwierząt, co wskazuje, iż szybkie nabywanie odporności na repelenty zapachowe jest cechą gatunkową dzika.

3. Szybka habituacja do środków odstraszających zapachem nie jest związana $\mathrm{z}$ charakterem środowiska w jakim dziki przebywają.
4. Repelenty zapachowe moga być przydatne do krótkotrwałego ograniczania szkód powodowanych przez dziki w uprawach kukurydzy jako element ochrony integrowanej, jednak nie zapobiegaja one skutecznie ani przed obecnością zwierząt na chronionej uprawie, ani przed ich żerowaniem.

\section{Literatura / References}

Andersen I.L., Naevdal E., Egil Bøe K., Bakken M. 2006. The significance of theories in behavioural ecology for solving problems in applied ethology - possibilities and limitations. Appl. Anim. Behav. Sci. 97 (1): 85-104.

Bibier C., Ruf T. 2005. Population dynamics in wild boar Sus scrofa: ecology, elasticity of growth rate and implications for the managment of pulsed resource consumers. J. Appl. Ecol. 42: 1203-1213.

Budny M., Panek M., Bresiński W., Kamieniarz R., Kolanoś B., Mąka H. 2010. Sytuacja zwierząt łownych w Polsce w latach 2009-2010 (wyniki monitoringu). Biul. Stacji Badawczej w Czempiniu 7, 62 ss.

Drickamer L.C., Vessey S.H. 1982. Animal Behavior. Concepts, Processes and Methods. PWS Publishers, Willard Grant Press, Boston, $510 \mathrm{pp}$.

Fruziński B. 1992. Dzik. Wyd. Cedrus, Warszawa, 248 ss.

Geisser H., Reyer H.U. 2004. Efficacy of hunting, feeding, and fencing to reduce crop damage by wild boars. J. Wildlife Manage. 68 (4): 939-946.

Godzińska E. 1992. Neuroetologiczne mechanizmy uczenia się i pamięci. Problemy 11 (555): 9-14.

Jezierski W. 2002. Elements of social and spatial organization of wild boar populations. Scientific Papers of Agricultural University of Poznań. Forestry 5: 39-67.

Kamieniarz R., Panek M. 2008. Zwierzęta łowne w Polsce na przełomie XX i XXI wieku. Stacja Badawcza OHZ PZŁ, Czempiń, 42 ss.

McClintock M.K. 2002. Pheromones, odors, and vasanas: the neuroendocrinology of social chemosignals in humans and animals. Hormones, Brain and Behaviour 1: 797-870.

Ustawa o produktach biobójczych z dnia 13 września 2002 roku. Dz. U. z 2002 r. Nr 175, poz. 1433.

Wegorek P., Giebel J. 2008. Działanie wybranych substancji aktywnych w odstraszaniu dzika (Sus scrofa L.) od żerowania w uprawach kukurydzy. [The effectiveness of selected active substances in keeping away wild boar (Sus strofa L.) from feeding on maize crops]. Prog. Plant Prot./Post. Ochr. Roślin 48 (3): 1002-1006.

Wegorek P. 2011. Damage Caused by Game Animals and other Mammal or Bird Species in Agricultural Crops and Woodlands Ethological Aspect, Prevention Possibilities. Inst. Ochr. Roślin - PIB, Poznań, 72 pp.

Wiepkema P.R. 1986. Remarks on the behaviour of wild boar. Appl. Anim. Behav. Sci. 15 (2): 179-180. 